\title{
Corrigendum: Integration of cytokine and heterologous receptor signaling pathways
}

Jelena S Bezbradica \& Ruslan Medzhitov

Nat. Immunol. 10, 333-339 (2009); published online 19 March 2009; corrected after print 18 May 2009

In the version of this article initially published, the second funding attribution in Acknowledgments is incorrect. The correct attribution is as follows: "Supported by Howard Hughes Medical Institute (J.S.B. and R.M.) and Damon Runyon Cancer Research Foundation (J.S.B)." The error has been corrected in the HTML and PDF versions of the article.

\section{Corrigendum: Cholesterol depletion associated with Leishmania major infec- tion alters macrophage CD40 signalosome composition and effector function}

Abdur Rub, Ranadhir Dey, Meenakshi Jadhav, Rohan Kamat, Santhosh Chakkaramakkil, Subrata Majumdar, Robin Mukhopadhyaya \& Bhaskar Saha

Nat. Immunol. 10, 273-280 (2009); published online 8 February 2009; corrected after print 18 May 2009

In the version of this article initially published, the GenBank accession number for the Indian human immunodeficiency virus 2 isolate is incorrect. The correct accession number is DQ307022. The error has been corrected in the HTML and PDF versions of the article.

\section{Erratum: The histone deacetylase HDAC11 regulates the expression of} interleukin 10 and immune tolerance

Alejandro Villagra, Fengdong Cheng, Hong-Wei Wang, Ildelfonso Suarez, Michelle Glozak, Michelle Maurin, Danny Nguyen, Kenneth L Wright, Peter W Atadja, Kapil Bhalla, Javier Pinilla-Ibarz, Edward Seto \& Eduardo M Sotomayor Nat. Immunol. 10, 92-100 (2009); published online 16 November 2008; corrected after print 18 May 2009

In the original version of the article published, the units for IL-12 in Figure $6 \mathrm{~b}$ are incorrect. The correct units should be '(ng/ml)'. The error has been corrected in the HTML and PDF versions of the article. 